\title{
BMJ Open Potential epidemiological impact of the 2017 American College of Cardiology/ American Heart Association high blood pressure guideline on the Chinese population: a cross-sectional study in rural areas of Liaoning Province
}

\author{
Yuanyuan Dong (10 , ${ }^{1}$ Zhaoqing Sun, ${ }^{1}$ Zhao Li, ${ }^{2}$ Xiaofan Guo, ${ }^{2}$ Guozhe Sun, ${ }^{2}$ \\ Yanxia Xie, ${ }^{3}$ Jia Zheng, ${ }^{3}$ Yue Dai, ${ }^{3}$ Yali Wang, ${ }^{3}$ Rongrong Guo, ${ }^{3}$ Liqiang Zheng (1) , ${ }^{3}$ \\ Yingxian Sun ${ }^{1}$
}

To cite: Dong Y, Sun Z, Li Z, et al. Potential epidemiological impact of the 2017 American College of Cardiology/American Heart Association high blood pressure guideline on the Chinese population: a crosssectional study in rural areas of Liaoning Province. BMJ Open 2020;10:e035900. doi:10.1136/ bmjopen-2019-035900

- Prepublication history for this paper is available online. To view these files, please visit the journal online (http://dx.doi org/10.1136/bmjopen-2019035900).

LZ and YS are joint senior authors.

Received 21 November 2019 Revised 07 April 2020 Accepted 30 July 2020

Check for updates

(c) Author(s) (or their employer(s)) 2020. Re-use permitted under CC BY-NC. No commercial re-use. See rights and permissions. Published by BMJ.

For numbered affiliations see end of article.

Correspondence to Dr Yingxian Sun; sunyingxian12@126.com and Dr Liqiang Zheng; liqiangzheng@126.com

\section{ABSTRACT}

Objectives The present study estimated the percentage of rural Chinese adults with hypertension and recommended pharmacological antihypertensive treatment according to the 2017 American College of Cardiology/ American Heart Association (ACC/AHA) guideline compared with the 2010 Chinese Guideline for the Management of Hypertension.

Design Cross-sectional study.

Setting Three counties in rural areas of northeastern China.

Participants A total of 11747 eligible individuals aged $\geq 35$ years from rural areas of northeastern China were selected for the present analysis.

Main outcome measures The percentage of rural Chinese adults with hypertension and recommended pharmacological antihypertensive treatment according to the 2017 ACC/AHA guideline and the 2010 Chinese Guideline for the Management of Hypertension, and the proportion of rural Chinese adults taking antihypertensive medication with blood pressure (BP) above the 2017 ACC/ AHA guideline and the 2010 Chinese guideline treatment goal.

Results The mean age of the study population was $53.9 \pm 10.8$ years and $53.7 \%$ of the participants were women. According to the 2017 ACC/AHA guideline and the 2010 Chinese guideline, the crude prevalence of hypertension was $72.2 \%$ and $49.8 \%$, respectively, and the percentage of recommended antihypertensive medications for rural Chinese adults was $56.4 \%$ and $51.4 \%$, respectively. Among these rural Chinese adults taking antihypertensive medications, $96.7 \%$ had above goal BP according to the 2017 ACC/AHA guideline compared with $86.1 \%$ with above goal BP according to the 2010 Chinese guideline.

Conclusion The present analysis demonstrated that compared with the 2010 Chinese guideline, the 2017 ACC/ AHA hypertension guideline will result in a substantial increase in the percentage of rural Chinese adults defined as having hypertension and a small increase
Strengths and limitations of this study

- This is the first study to analyse the potential impact of the 2017 American College of Cardiology/ American Heart Association (ACC/AHA) guideline on the prevalence of hypertension, the recommended antihypertensive medications and the above goal blood pressure (BP) in rural areas of Liaoning Province, China.

- The atherosclerotic cardiovascular disease risk calculation model used in this study is more consistent with the Chinese population than is the pooled cohort risk formula recommended by the $2017 \mathrm{ACC} /$ AHA guideline.

- This study only analyses a group of individuals from rural areas of Liaoning Province, and more diverse representative samples are needed to analyse the further impact of the 2017 ACC/AHA guideline on hypertension management in China.

- BP in this study was measured three times on the same day and was not measured on different days.

in the percentage of adults who are recommended antihypertensive medications. More intensive management is suggested to improve the control rate of hypertension among rural Chinese adults.

\section{INTRODUCTION}

On 13 November 2017, the American College of Cardiology and American Heart Association (ACC/AHA) issued the Guideline for the Prevention, Detection, Evaluation and Management of High Blood Pressure in Adults. ${ }^{1}$ This guideline substantially updated the 2003 JNC-7 guideline after 14 years. $^{2}$ The 2017 ACC/AHA guideline substantially modified and described the definition 
of hypertension and recommended blood pressure (BP) thresholds for the initiation of antihypertensive medications and BP target goals in detail. One of the most notable changes is the definition of hypertension, which was modified from systolic blood pressure (SBP)/ diastolic blood pressure (DBP) $\geq 140 / 90 \mathrm{~mm} \mathrm{Hg}$ to SBP/ DBP $\geq 130 / 80 \mathrm{~mm} \mathrm{Hg}$. The new definition will increase the prevalence of hypertension from $31.9 \%$ to $45.6 \%$, and the number of patients with hypertension will increase by 31.1 million in the USA. ${ }^{3}$ In addition, according to the 2017 ACC/AHA guideline, the proportion of people for whom antihypertensive medication is recommended will slightly increase by $1.9 \%$ (from $34.3 \%$ to $36.2 \%$ ). ${ }^{3}$ Among US adults taking antihypertensive medication, the proportion of patients with above goal $\mathrm{BP}$ will also increase from $39.0 \%$ to $53.4 \%$, and the control rate of hypertension will be lower. This new hypertension guideline has concerned cardiologists and public policymakers in this research field of hypertension. How should one face this new guideline, and what is its potential impact on local hypertension management? All of these concerns will remain hot topics for a long period of time.

In the last decade, the prevalence and incidence of hypertension have increased steeply in China, especially in rural areas. ${ }^{4-6}$ China is experiencing a high prevalence with a low rate of treatment and control of hypertension. ${ }^{4}$ Recently, using a representative sample of more than 1.7 million (aged $35-75$ years), Jiang et al revealed that the prevalence of hypertension was $44.7 \%$, whereas the rates of taking hypertensive medications and achieving BP goals in patients with hypertension were $30.1 \%$ and $7.2 \%,{ }^{7}$ respectively.

The present study was performed in a representative sample of $\geq 35$-year-old adults from rural areas of Liaoning Province to analyse the prevalence of hypertension and the rates of recommended antihypertensive medication treatment and above goal BP according to the 2017 ACC/ AHA guideline and the 2010 Chinese guideline, and to discuss the potential impact of the 2017 ACC/AHA hypertension guideline on the current epidemiological characteristics of the prevention and treatment of hypertension in rural areas of China.

\section{METHODS}

\section{Study sample}

Liaoning Province is located in northeastern China. The study population was derived from the "Northeast China Rural Cardiovascular Health Study' cohort, which was described in a previous study. ${ }^{68}$ The baseline survey adopted a multistage stratified cluster random sampling method. From January to August 2013, 11956 ( $\geq 35$ years) eligible subjects (response rate of $85.3 \%$ ) from three counties (a total of 26 rural villages), namely, Dawa, Zhangwu and Liaoyang in Liaoning Province were recruited to carry out epidemiological studies of cardiovascular disease (CVD) in rural areas of northeastern China. Each participant completed a baseline questionnaire, physical examination, laboratory examination and blood sample collection after written informed consent.

For the present study, we excluded individuals who lacked the following information: participants who did not have three BP measurements or who were missing data on antihypertensive medication use $(\mathrm{n}=108)$, and on variables (gender, age, smoking, total cholesterol, high density cholesterol, family history of diabetes and CVD) used to calculate the risk of atherosclerotic cardiovascular disease (ASCVD) ( $\mathrm{n}=101)$. Finally, 11747 individuals were left for the present analysis.

\section{BP measurement and antihypertensive medication use}

A trained and certified observer used an AHA protocol to perform BP measurements, and participants were advised to avoid caffeinated beverages, alcohol consumption, cigarette smoking and exercise for at least $30 \mathrm{~min}$ and to rest for at least $5 \mathrm{~min}$ before measurement. BP was measured while individuals were in a seated position in a quiet local room. BP measurements were performed using a standard electronic automated BP monitor (HEM-907; OMRON, Tokyo, Japan) with one of three cuff sizes (regular adult, large or thigh) chosen on the basis of arm circumference. BP was measured three times for each individual at 2-minute intervals on the same day. The mean of three BP measurements was calculated as the individual's BP value and was used in all analyses. The investigator obtained data on the use of antihypertensive medication by asking the questions 'Did you take antihypertensive medication in the past 2 weeks?' and 'What is the type and name of the antihypertensive medication?'

\section{Definition of hypertension, recommended antihypertensive medication and above goal BP standards}

The definition of hypertension, the recommended initial treatment and above goal BP standards will be strictly in accordance with the 2017 ACC/AHA guideline and the 2010 Chinese guideline (table 1).

\section{Cardiovascular risk factors and ASCVD risk calculation}

History of CVD was defined by self-reported prior diagnosis of coronary heart disease, stroke or heart failure. Among individuals without CVD history, because the pooled cohort risk model recommended by the 2017 ACC/AHA guideline cannot be used for Chinese individuals, the present study selected the ASCVD risk calculation model developed by Yang et at to assess the risk of ASCVD and participants were categorised into the following groups: $<5 \%, 5 \%-<10 \%, 10 \%-<20 \%, \geq 20 \%$. Low-risk population was defined as ASCVD risk $<5 \%$, and moderate risk population was defined as ASCVD risk $5 \%-<10 \%$. High-risk population was defined as having a history of CVD or ASCVD risk $\geq 10 \%$. Diabetes was defined as a previous history of self-reported diabetes or fasting blood glucose $\geq 7.0 \mathrm{mmol} / \mathrm{L}$. Chronic kidney disease (CKD) was defined as an estimated glomerular filtration rate $<60 \mathrm{~mL} / \mathrm{min} / 1.73 \mathrm{~m}^{2}$, which was calculated by CKDEPI equations. ${ }^{10}$ 
Table 1 Blood pressure levels used to define hypertension, recommend antihypertensive medication and treatment goa according to the 2017 ACC/AHA guideline and the 2010 Chinese guideline

\section{Guideline-definition of hypertension}

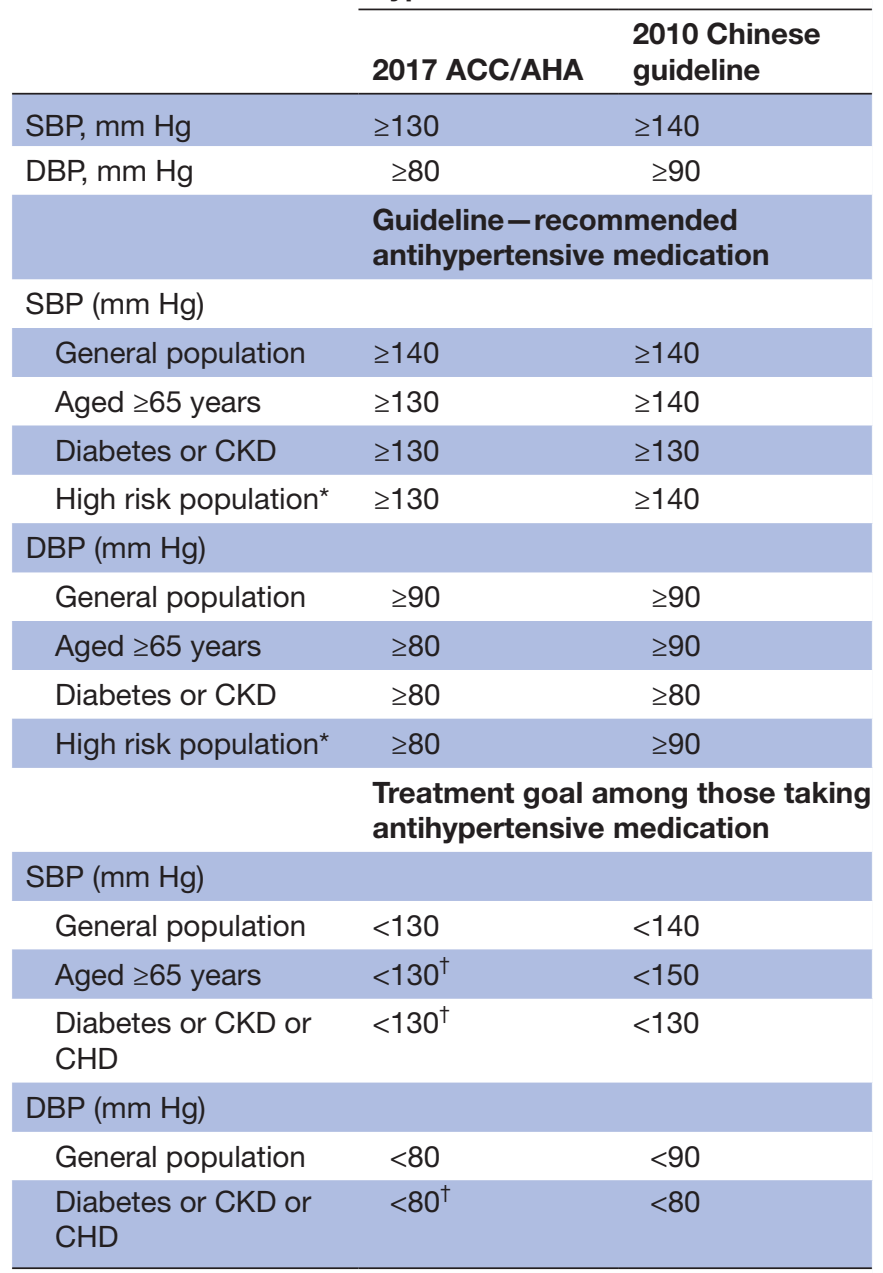

*High cardiovascular risk is defined as a history of cardiovascular disease (coronary heart disease, stroke and heart failure) or 10-year predicted ASCVD risk $\geq 10 \%$.

$\dagger$ No specific blood pressure threshold is provided in the guideline for this population.

ACC/AHA, American College of Cardiology/American Heart Association; ASCVD, atherosclerotic cardiovascular disease; $\mathrm{CHD}$, coronary heart disease; CKD, chronic kidney disease; DBP, diastolic blood pressure; SBP, systolic blood pressure.

\section{Statistical analysis}

Continuous variables were reported as the means and SDs, and categorical variables were expressed as frequencies and percentages. We categorised the participants into five groups based on BP levels and antihypertensive medication use, including four groups not taking antihypertensive drugs (SBP/DBP $\geq 140 / 90,130-139 / 80-89$, $120-129 /<80$ and $<120 /<80 \mathrm{~mm} \mathrm{Hg}$ ), and a group taking antihypertensive drugs. These BP levels represented the BP stages in the 2017 ACC/AHA guideline. Subgroups were compared by $\chi^{2}$ tests for categorical variables or one-way analysis of variance for continuous variables. We calculated the percentage of adults with hypertension in rural areas of China and the percentage of people for whom antihypertensive medication is recommended based on the 2017 ACC/AHA guideline, the 2010 Chinese guideline and the 2017 ACC/AHA guideline but not the 2010 Chinese guideline. We also calculated the percentage of adults taking antihypertensive medication with BP above goal according to the 2017 ACC/ AHA guideline, the 2010 Chinese guideline and the 2017 ACC/AHA guideline but not the 2010 Chinese guideline. These calculations were performed in the general population and in different subgroups (such as age (35-44, $45-54,55-64,65-74, \geq 75$ years), sex (men and women), ethnicity (Han, Mongolian and others) and history of CVD (yes or no)). All analyses were performed with SPSS statistical software V.13.0 and SAS statistical software V.9.2. A $\mathrm{p}$ value of less than 0.05 was accepted as indicating statistical significance.

\section{Patient and public involvement}

There was no patient or public involvement in the design of this study.

\section{RESULTS}

The mean age of the study population was $53.9 \pm 10.8$ years, and $53.7 \%$ of those were women. A total of $15.2 \%, 18.3 \%$, $16.7 \%$ and $35.5 \%$ of Chinese adults not taking antihypertensive medications had SBP/DBP levels of $<120 / 80$, $120-129 /<80, \quad 130-139 / 80-89$ and $\geq 140 / 90 \mathrm{~mm} \mathrm{Hg}$, respectively (table 2 ). A total of $14.3 \%$ of the study population was taking antihypertensive medication. The baseline characteristics of the study participants according to different BP subgroups are shown in table 2. With increasing BP values, their age, the total cholesterol levels and the prevalence of diabetes also increased (table 2).

Based on the 2010 Chinese guideline, the prevalence of hypertension among rural adults in Liaoning Province was $49.8 \%$. According to the 2017 ACC/AHA guideline, the prevalence of hypertension was as high as $72.2 \%$, an increase of 22.4\% (table 3). Table 3 also shows the differences in the prevalence of hypertension among different subgroups according to the 2010 Chinese guideline and the 2017 American ACC/AHA guideline. The results showed that there was a difference between the two guidelines in diagnosing the prevalence of hypertension in the subgroups of men, lower age group, without CVD history and ASCVD risk $<10 \%(\mathrm{p}<0.05)$.

Table 4 shows the differences in the proportion of people for whom antihypertensive medication is recommended among different subgroups according to the 2017 ACC/AHA guideline and the 2010 Chinese guideline. According to the 2017 ACC/AHA guideline, 56.4\% of the study population will be recommended antihypertensive medication, an increase of $5.0 \%$ relative to the $51.4 \%$ recommended by the 2010 Chinese guideline (table 4). Non-pharmacological therapy is advised for 
Table 2 Baseline characteristics of rural Chinese adults by blood pressure levels and antihypertensive medication use $(n=11747)$

\begin{tabular}{|c|c|c|c|c|c|c|}
\hline & \multicolumn{4}{|c|}{$\begin{array}{l}\text { SBP/DBP categories in } \mathrm{mm} \mathrm{Hg} \text { among Chinese adults } \\
\text { not taking antihypertensive medication }\end{array}$} & \multirow[b]{2}{*}{$\begin{array}{l}\text { Taking antihypertensive medication } \\
(\mathrm{n}=1682)\end{array}$} & \multirow[b]{2}{*}{ P value } \\
\hline & $\begin{array}{l}<120 / 80 \\
(n=1787)\end{array}$ & $\begin{array}{l}120-129 /<80 \\
(n=2149)\end{array}$ & $\begin{array}{l}130-139 / 80-89 \\
(n=1961)\end{array}$ & $\begin{array}{l}\geq 140 / 90 \\
(n=4168)\end{array}$ & & \\
\hline \multicolumn{7}{|l|}{ Population characteristics } \\
\hline Age (years) & $48.8 \pm 9.7$ & $50.2 \pm 9.9$ & $52.1 \pm 10.1$ & $56.9 \pm 10.6$ & $58.5 \pm 9.7$ & $<0.001$ \\
\hline \multicolumn{7}{|l|}{ Ethnic (\%) } \\
\hline Han & 95.0 & 94.1 & 95.3 & 94.2 & 95.1 & \\
\hline Mongolian & 2.1 & 2.5 & 1.9 & 3.3 & 2.6 & \\
\hline Others & 2.9 & 3.4 & 2.8 & 2.5 & 2.3 & $<0.001$ \\
\hline Current smoking (\%) & 34.5 & 39.2 & 41.2 & 42.6 & 34.7 & $<0.001$ \\
\hline Glucose (mmol/L) & $5.5 \pm 1.2$ & $5.7 \pm 1.3$ & $5.8 \pm 1.4$ & $6.1 \pm 1.8$ & $6.4 \pm 2.0$ & $<0.001$ \\
\hline eGFR (mL/min/1.73 m²) & $95.8 \pm 13.8$ & $95.9 \pm 15.1$ & $95.3 \pm 14.1$ & $92.3 \pm 16.7$ & $87.2 \pm 16.9$ & $<0.001$ \\
\hline $\mathrm{SBP}(\mathrm{mm} \mathrm{Hg})$ & $112.1 \pm 5.9$ & $124.6 \pm 3.3$ & $134.5 \pm 2.9$ & $157.7 \pm 17.0$ & $164.6 \pm 23.5$ & $<0.001$ \\
\hline $\mathrm{DBP}(\mathrm{mm} \mathrm{Hg})$ & $69.2 \pm 5.8$ & $76.2 \pm 6.3$ & $79.2 \pm 6.2$ & $88.2 \pm 10.5$ & $91.3 \pm 12.5$ & $<0.001$ \\
\hline 10-year ASCVD predicted risk & $0.04 \pm 0.05$ & $0.06 \pm 0.05$ & $0.08 \pm 0.06$ & $0.16 \pm 0.10$ & $0.21 \pm 0.11$ & $<0.001$ \\
\hline High-risk population† (\%) & 10.2 & 17.3 & 32.4 & 68.2 & 86.0 & $<0.001$ \\
\hline \multicolumn{7}{|l|}{ ASCVD risk (\%) } \\
\hline$<5 \%$ & 77.3 & 57.6 & 38.1 & 11.1 & 3.1 & \\
\hline $5 \%-<10 \%$ & 15.9 & 28.1 & 32.1 & 22.3 & 12.5 & \\
\hline
\end{tabular}

*Difference between subgroups, $\mathrm{p}<0.05$.

†High cardiovascular risk is defined as a history of cardiovascular disease (coronary heart disease, stroke and heart failure) or 10-year predicted ASCVD risk $\geq 10 \%$.

ASCVD, atherosclerotic cardiovascular disease; DBP, diastolic blood pressure; eGFR, estimated glomerular filtration rate; HDL, high-density lipoprotein; SBP, systolic blood pressure; TC, total cholesterol.

$15.8 \%$ of study participants diagnosed with hypertension according to the 2017 ACC/AHA guideline.

According to the 2010 Chinese hypertension guideline, the percentage of above goal BP among patients taking antihypertensive medications reached $86.1 \%$ (table 5). According to the 2017 ACC/AHA guideline, it was as high as $96.7 \%$. This proportion significantly increased by $10.6 \%$. The differences in the rate of above goal BP between the two guidelines were also observed in different subgroups (table 5).

\section{DISCUSSION}

The present study, using a representative population of rural areas of Liaoning Province, revealed the potential impact of the 2017 ACC/AHA guideline on the epidemic characteristics of hypertension. Based on the 2010 China hypertension guideline and the 2017 ACC/AHA guideline, the prevalence of hypertension in rural areas of
Liaoning Province increased from $49.8 \%$ to $72.2 \%$, the proportion of people for whom antihypertensive medication was recommended increased from $51.4 \%$ to $56.4 \%$ and the proportion of above goal BP among patients taking antihypertensive medications increased from $86.1 \%$ to $96.7 \%$ (figure 1). More intensive management for hypertension is necessary for rural adults in Liaoning Province in China.

In recent decades, the prevalence of hypertension among adults in China has increased dramatically, and it has become an important public health issue. A recent China Patient-centered Evaluative Assessment of Cardiac Events (PEACE) Study including more than 1.7 million people indicated that the prevalence of hypertension was $44.7 \%$ (95\% CI: $44.6 \%-44.8 \%$ ) among adults aged $\geq 35$ years. ${ }^{7}$ Recently, the incidence of hypertension has also shown a steep increasing trend, especially in rural areas of northeastern China. ${ }^{56}$ This study found that according to 
Table 3 Prevalence of hypertension among rural Chinese adults based on the 2017 ACC/AHA guideline and the 2010 Chinese guideline (\%)

\begin{tabular}{|c|c|c|c|}
\hline & $\begin{array}{l}2017 \text { ACC/AHA } \\
\text { guideline }\end{array}$ & $\begin{array}{l}2010 \text { Chinese } \\
\text { guideline }\end{array}$ & $\begin{array}{l}\text { Difference } \\
\text { (2017 ACC/AHA but not } 2010 \text { Chinese guideline) }\end{array}$ \\
\hline Overall ( $n=11747)$ & 72.2 & 49.8 & 22.4 \\
\hline \multicolumn{4}{|l|}{ Age (year) } \\
\hline $35-44(n=2793)$ & 56.1 & 27.3 & 28.8 \\
\hline $45-54(n=3644)$ & 69.2 & 43.9 & 25.3 \\
\hline $55-64(n=3537)$ & 81.0 & 61.9 & 19.1 \\
\hline $65-74(n=1405)$ & 85.8 & 72.2 & 13.5 \\
\hline$\geq 75(n=368)$ & 88.9 & 77.2 & $11.7^{*}$ \\
\hline \multicolumn{4}{|l|}{ Sex } \\
\hline Men $(n=5441)$ & 76.7 & 52.8 & 23.9 \\
\hline Women $(n=6306)$ & 68.4 & 47.2 & $21.2^{*}$ \\
\hline \multicolumn{4}{|l|}{ Ethnic } \\
\hline $\operatorname{Han}(n=11113)$ & 72.3 & 49.7 & 22.6 \\
\hline Mongolian $(n=308)$ & 72.7 & 58.8 & 14.0 \\
\hline Others $(n=326)$ & 69.3 & 44.2 & $25.2^{*}$ \\
\hline \multicolumn{4}{|l|}{ ASCVD risk } \\
\hline$<5 \%(\mathrm{n}=3882)$ & 42.8 & 13.2 & 29.6 \\
\hline $5 \%-<10 \%(n=2658)$ & 74.4 & 42.9 & 31.5 \\
\hline $10 \%-<20 \%(n=3055)$ & 90.0 & 72.6 & 17.4 \\
\hline$\geq 20 \%(n=2152)$ & 97.3 & 92.0 & $5.3^{*}$ \\
\hline \multicolumn{4}{|l|}{ The history of CVD† } \\
\hline Yes $(n=994)$ & 83.7 & 71.2 & 12.5 \\
\hline No $(n=10753)$ & 71.2 & 47.8 & $23.3^{*}$ \\
\hline
\end{tabular}

*Difference between subgroups, $p<0.05$.

†Defined as a history of cardiovascular disease (coronary heart disease, stroke and heart failure).

ACC/AHA, American College of Cardiology/American Heart Association; ASCVD, atherosclerotic cardiovascular disease; CVD, cardiovascular disease.

the 2010 Chinese hypertension guideline, the prevalence of hypertension among adults ( $\geq 35$ years) in rural areas of Liaoning Province was $49.8 \%$, with one in two people having hypertension. However, according to the 2017 ACC/AHA guideline, the prevalence of hypertension in this region will increase to a level as high as $72.2 \%$, with a relative increase of $45 \%$, which is similar to US data. ${ }^{3}$ Using the 2011-2014 National Health and Nutrition Examination Survey (NHANES) population data, Muntner et al showed that the 2017 American ACC/AHA guideline will increase the prevalence of hypertension in the USA from $31.9 \%$ (JNC-7 guideline) to $45.6 \%$, with a relative increase of $43.0 \%{ }^{3}$ According to the 2017 ACC/AHA guideline, more individuals with $\mathrm{BP} \geq 130-139 / 80-89 \mathrm{~mm} \mathrm{Hg}$ will be newly diagnosed with hypertension. China is facing enormous public health challenges with a large population. High levels of attention should be paid to strengthening the management of hypertension among rural adults in China to reduce the burden of hypertension and its complications on treatment, medical expenditures and the national economy. However, there is no doubt that the diagnosis of hypertension provides an opportunity for healthcare providers and patients to discuss the value of non-pharmacological treatment in lowering BP, to implement recommended lifestyle changes and to emphasise that $\mathrm{BP}$ is a potential controlled hazard of CVD, end-stage renal disease, subclinical atherosclerosis and all-cause mortality. Therefore, we should also pay more attention to the positive impact of a new definition of hypertension on rural adults in China based on the 2017 ACC/AHA guideline.

The 2017 ACC/AHA guideline has drastically changed the recommended treatment for patients with hypertension on the basis of JNC-7, which recommends lifestyle treatment for the general population at a $\mathrm{BP}$ of 130-139/80-89 mm Hg. ${ }^{12}$ Additional initial medical treatment is recommended for high-risk patients (CVD, CKD, diabetes and so on), including high ASCVD risk $(\geq 10 \%)$. NHANES data analysis results show that, according to the 2017 ACC/AHA guideline, the recommended antihypertensive medication for US adults will increase from $34.3 \%$ to $36.2 \%$, with a small increase of $1.9 \% .^{3}$ Our study 
Table 4 Percentage of recommended antihypertensive medications among rural Chinese adults based on the 2017 ACC/AHA guideline and the 2010 Chinese guideline (\%)

\begin{tabular}{|c|c|c|c|}
\hline & \multicolumn{2}{|c|}{ Recommended antihypertensive medications } & \multirow[b]{2}{*}{$\begin{array}{l}\text { Difference } \\
\text { (2017 ACC/AHA but not } 2010 \text { Chinese guideline) }\end{array}$} \\
\hline & $\begin{array}{l}2017 \text { ACC/AHA } \\
\text { guideline }\end{array}$ & $\begin{array}{l}2010 \text { Chinese } \\
\text { guideline }\end{array}$ & \\
\hline Overall $(n=11747)$ & 56.4 & 51.4 & 5.0 \\
\hline \multicolumn{4}{|l|}{ Age (years) } \\
\hline $35-44(n=2793)$ & 28.8 & 28.4 & 0.4 \\
\hline $45-54(n=3644)$ & 47.6 & 45.4 & 2.2 \\
\hline $55-64(n=3537)$ & 72.4 & 63.7 & 8.7 \\
\hline $65-74(n=1405)$ & 85.6 & 74.3 & 11.3 \\
\hline$\geq 75(n=368)$ & 88.9 & 80.7 & $8.2^{*}$ \\
\hline \multicolumn{4}{|l|}{ Sex } \\
\hline Men $(n=5441)$ & 61.7 & 54.4 & 7.3 \\
\hline Women $(n=6306)$ & 52 & 48.9 & $3.0^{*}$ \\
\hline \multicolumn{4}{|l|}{ Ethnic } \\
\hline $\operatorname{Han}(n=11113)$ & 56.4 & 51.3 & 5.1 \\
\hline Mongolian $(n=308)$ & 63.0 & 61.4 & 1.6 \\
\hline Others $(n=326)$ & 51.3 & 46 & 5.2 \\
\hline \multicolumn{4}{|l|}{ ASCVD risk } \\
\hline$<5 \%(\mathrm{n}=3882)$ & 14.3 & 13.6 & 0.6 \\
\hline $5 \%-<10 \%(n=2658)$ & 46.4 & 44.6 & 1.8 \\
\hline $10 \%-<20 \%(n=3055)$ & 90.0 & 75.4 & 14.6 \\
\hline$\geq 20 \%(n=2152)$ & 97.3 & 94.1 & $3.3^{*}$ \\
\hline \multicolumn{4}{|l|}{ The history of CVD† } \\
\hline Yes $(n=994)$ & 83.7 & 72.7 & 11.0 \\
\hline No $(n=10753)$ & 53.9 & 49.5 & $4.5^{\star}$ \\
\hline
\end{tabular}

*Difference between subgroups $p<0.05$.

†Defined as a history of cardiovascular disease (coronary heart disease, stroke and heart failure).

ACC/AHA, American College of Cardiology/American Heart Association; ASCVD, atherosclerotic cardiovascular disease; CVD, cardiovascular disease.

suggests that $56.4 \%$ of the population will be recommended antihypertensive medication, higher than the $51.4 \%$ recommended by the 2010 Chinese hypertension guideline, with a $5.0 \%$ increase. In fact, an additional $5.0 \%$ of people taking antihypertensive drugs will constitute a large group and need far more social and medical resources in China. Although there is some evidence from clinical trials suggesting that more benefit will be achieved by lowering BP below $120 / 80 \mathrm{~mm} \mathrm{Hg}$, there is no direct evidence from Chinese samples. ${ }^{8}$ However, regardless of the guideline recommendations we consider, we must pay more attention to the rate of taking antihypertensive medication and obtaining regular treatment as quickly as possible, which are urgent issues in China. There are some effective and affordable methods for enhanced BP monitoring, treatment and control programmes in the Chinese rural regions, such as free physical examinations for residents more than 60 years old once a year in the primary care centre, home BP monitoring two times a day for patients with hypertension, the promotion of popular science on the prevention and treatment of hypertension on TV and the WeChat official account, follow-up via telephone by village doctors and online consultations on the internet healthcare platform. We believe that a public health strategy involving educational and environmental interventions should be targeted at village doctors and others responsible for primary care in rural areas as well as the rural population.

An improvement in the rate of hypertension control is a serious challenge that we must face. The China PEACE Study showed that the control rate of hypertension $(\geq 35$ years) was $7.2 \% .^{7}$ Our study indicated that according to the 2010 Chinese guideline, the above goal BP among rural patients with hypertension in Liaoning Province is $86.1 \%$ (control rate 13.9\%); however, based on the 2017 American ACC/AHA guideline, it will be as high as $96.7 \%$ (control rate is only $3.3 \%$ ). NHANES data show the above goal BP will increase from 39.0\% (JNC-7 guideline) to $53.4 \%$ (2017 ACC/AHA guideline), with a relative increase of $30.0 \% .^{3}$ Our data show that a relative increase 
Table 5 Proportion of rural Chinese adults taking antihypertensive medication with blood pressure above the 2017 ACC/AHA guideline and the 2010 Chinese guideline treatment goal (\%)

\begin{tabular}{|c|c|c|c|}
\hline & \multicolumn{2}{|c|}{ Blood pressure above goal according to: } & \multirow{2}{*}{$\begin{array}{l}\text { Difference } \\
\text { (2017 ACC/AHA but not } 2010 \text { Chinese guideline }\end{array}$} \\
\hline & 2017 ACC/AHA guideline & 2010 Chinese guideline & \\
\hline Overall $(n=1682)$ & 96.7 & 86.1 & 10.6 \\
\hline $35-44(n=142)$ & 95.8 & 79.6 & 16.2 \\
\hline $45-54(n=427)$ & 94.6 & 87.4 & 7.3 \\
\hline$\geq 75(n=60)$ & 96.7 & 78.3 & $18.3^{*}$ \\
\hline \multicolumn{4}{|l|}{ Sex } \\
\hline Men $(n=713)$ & 97.6 & 88.4 & 9.3 \\
\hline Women $(n=969)$ & 96.1 & 84.5 & 11.6 \\
\hline \multicolumn{4}{|l|}{ ASCVD risk } \\
\hline$<5 \%(n=52)$ & 67.3 & 25.0 & 42.3 \\
\hline $5 \%-<10 \%(n=210)$ & 91.4 & 74.8 & 16.7 \\
\hline $10 \%-<20 \%(n=601)$ & 96.8 & 83.9 & 13.0 \\
\hline$\geq 20 \%(n=819)$ & 99.9 & 94.6 & $5.3^{*}$ \\
\hline \multicolumn{4}{|l|}{ The history of CVD† } \\
\hline Yes $(n=1365)$ & 98.4 & 87.1 & 11.4 \\
\hline No $(n=317)$ & 96.3 & 85.9 & 10.4 \\
\hline
\end{tabular}

*Difference between subgroups $\mathrm{p}<0.05$.

†Defined as a history of cardiovascular disease (coronary heart disease, stroke and heart failure).

ACC/AHA, American College of Cardiology/American Heart Association; ASCVD, atherosclerotic cardiovascular disease; CVD, cardiovascular disease.

of $12.3 \%$ in the above goal $\mathrm{BP}$ with reference to the 2017 ACC/AHA guideline, which is lower than the change in US data. The difference is partly explained by the fact that the rate of above goal $\mathrm{BP}$ is too high and that the

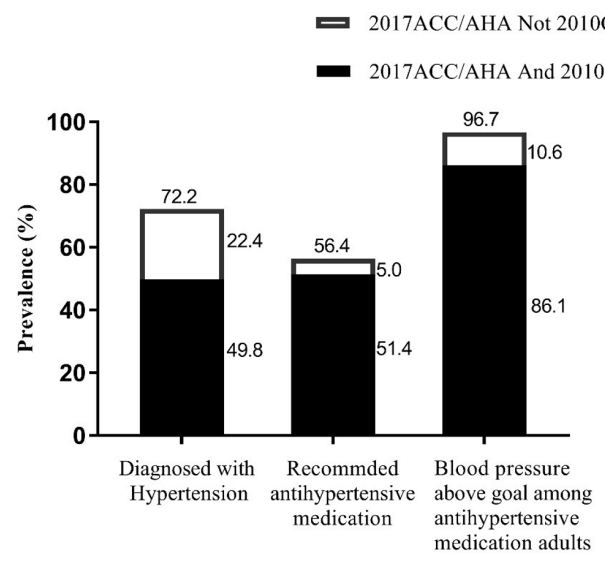

Figure 1 Prevalence of diagnosed with hypertension, recommendation for pharmacological antihypertensive treatment and blood pressure above goal among rural Chinese adults according to the 2017 American College of Cardiology/American Heart Association guideline and the 2010 Chinese guideline. control rate of hypertension is extremely poor in rural areas of China.

The strength of the present study is that it is the first study to analyse the potential impact of the 2017 ACC/ AHA guideline on the prevalence of hypertension, the recommended antihypertensive medications and the above goal BP in rural areas of Liaoning Province, which will provide important supporting data for the future prevention and treatment of hypertension. However, there are still some limitations in this study. First, instead of using the pooled cohort risk formula recommended by the 2017 ACC/AHA guideline, the ASCVD formula used in this study, developed by Yang $e t a l,{ }^{9}$ is more consistent with the characteristics of the Chinese population. Second, this study only analysed a group of individuals from rural areas of Liaoning Province, and more diverse representative samples are needed to analyse the further impact of the 2017 ACC/AHA guideline on hypertension management in China. Finally, BP in this study was measured three times on the same day during a single visit because the number of the participants was large, but the investigators were limited. The 2017 ACC/AHA guideline emphasised the importance of accurate BP measurement in its definition of hypertension and recommended that 
the diagnosis of hypertension be based on the average of multiple BP measurements obtained during two or more visits. However, BP was not measured on different days, which may induce a misclassification bias.

\section{CONCLUSION}

In conclusion, our study found that the 2017 ACC/AHA hypertension guideline has a potential impact on the prevalence of hypertension, the recommended antihypertensive medications and the control rate of the rural Chinese population with hypertension. The 2017 ACC/ AHA guideline will significantly increase the prevalence of hypertension $(22.4 \%)$, while the recommended antihypertensive medication in this population will increase slightly $(5.0 \%)$ among rural adults in Liaoning Province. We should pay more attention to the positive impact from the 2017 ACC/AHA guideline on rural Chinese adults and further do some cost-effectiveness analysis regarding the guideline. Regardless, we should positively focus on the control and management of hypertension and further reduce the burden of chronic disease in China.

\section{Author affiliations}

${ }^{1}$ Department of Cardiology, Shengjing Hospital of China Medical University, Shenyang, Liaoning, China

${ }^{2}$ Department of Cardiology, the First Affiliated Hospital of China Medical University, Shenyang, Liaoning, China

${ }^{3}$ Department of Clinical Epidemiology, Library, Shengjing Hospital of China Medical University, Shenyang, Liaoning, China

Acknowledgements Thanks to the American Journal Experts for their contribution to the copyediting of this manuscript.

Contributors YS and LZ designed and conducted the study and revised the manuscript. YD analysed the data and wrote the manuscript. ZL, XG and GS collected the data. YX, JZ, YD, YW and RG analysed the data. ZS managed the study. All authors read and approved the final manuscript.

Funding This research was partly supported by funds from National Nature Science Foundation of China (No. 81773510), Nature Science Foundation of Liaoning Province (No. 20170541048) and National Key R\&D Program of China (No.2018YFC1311600).

Competing interests None declared.

Patient and public involvement Patients and/or the public were not involved in the design, or conduct, or reporting, or dissemination plans of this research.

Patient consent for publication Not required.
Ethics approval The research project was approved by the Ethics Committee of China Medical University.

Provenance and peer review Not commissioned; externally peer reviewed.

Data availability statement The datasets generated and/or analysed during the current study are available from the corresponding author on reasonable request.

Open access This is an open access article distributed in accordance with the Creative Commons Attribution Non Commercial (CC BY-NC 4.0) license, which permits others to distribute, remix, adapt, build upon this work non-commercially, and license their derivative works on different terms, provided the original work is properly cited, appropriate credit is given, any changes made indicated, and the use is non-commercial. See: http://creativecommons.org/licenses/by-nc/4.0/.

ORCID iDs

Yuanyuan Dong http://orcid.org/0000-0002-8274-6484

Liqiang Zheng http://orcid.org/0000-0003-0101-9398

\section{REFERENCES}

1 Whelton PK, Carey RM, Aronow WS, et al. 2017 ACC/AHA/AAPA/ ABC/ACPM/AGS/APhA/ASH/ASPC/NMA/PCNA guideline for the prevention, detection, evaluation, and management of high blood pressure in adults: Executive summary: a report of the American College of Cardiology/American heart association Task force on clinical practice guidelines. Hypertension 2018;71:1269-324.

2 Chobanian AV, Bakris GL, Black HR, et al. The seventh report of the joint National Committee on prevention, detection, evaluation, and treatment of high blood pressure: the JNC 7 report. JAMA 2003;289:2560-72.

3 Muntner P, Carey RM, Gidding S, et al. Potential US population impact of the 2017 ACC/AHA high blood pressure guideline. Circulation 2018;137:109-18.

$4 \mathrm{Xi} \mathrm{B}$, Liang Y, Mi J. Hypertension trends in Chinese children in the National surveys, 1993 to 2009. Int J Cardiol 2013;165:577-9.

5 Sun Z, Zheng L, Wei Y, et al. The prevalence of prehypertension and hypertension among rural adults in Liaoning Province of China. Clin Cardiol 2007;30:183-7.

6 Li Z, Guo X, Zheng L, et al. Grim status of hypertension in rural China: results from Northeast China rural cardiovascular health study 2013. J Am Soc Hypertens 2015;9:358-64.

7 Lu J, Lu Y, Wang X, et al. Prevalence, awareness, treatment, and control of hypertension in China: data from 1.7 million adults in a population-based screening study (China PEACE million persons project). The Lancet 2017;390:2549-58.

8 Guan X, Sun G, Zheng L, et al. Associations between metabolic risk factors and body mass index, waist circumference, waist-to-height ratio and waist-to-hip ratio in a Chinese rural population. $J$ Diabetes Investig 2016;7:601-6.

9 Yang X, Li J, Hu D, et al. Predicting the 10-year risks of atherosclerotic cardiovascular disease in Chinese population: the China-PAR project (prediction for ASCVD risk in China). Circulation 2016;134:1430-40.

10 Levey AS, Bosch JP, Lewis JB, et al. A more accurate method to estimate glomerular filtration rate from serum creatinine: a new prediction equation. modification of diet in renal disease Study Group. Ann Intern Med 1999;130:461-70. 